\title{
PROIBIÇÃO DA PRÁTICA DE TORTURA NA CORTE INTERAMERICANA DE DIREITOS HUMANOS
}

\author{
Isteissi Aires Garcia Somenzari ${ }^{1}$
}

\section{RESUMO}

Ainda que a jurisprudência da Corte Interamericana de Direitos Humanos $^{2}$, se comparada a Corte Européia de Direitos Humanos, seja menos desenvolvida e consolidada, bastante relevante tem sido sua contribuição para a efetivação desses direitos na região. A proibição da prática da tortura, por exemplo, tem ganhado tratamento relevante no Direito Internacional. Tal proibição tem se consolidado com o status de norma cogente, denominada de jus cogens, principalmente nos sistemas regionais de proteção dos direitos humanos. Embora, nesta perspectiva, a jurisprudência do sistema europeu esteja a frente daquela desenvolvida na $\mathrm{CIDH}$, o reconhecimento da proibição da prática de tortura como jus cogens já foi alcançado também nas Américas, sendo, neste caso, uma norma absoluta e inafastável, mesmo em casos tidos como de emergência.

\section{ABSTRACT}

Even though the jurisprudence of the Inter-American Court of Human Rights is less consolidated and developed than the European Court of Human Rights, its approach to realize these rights in the region has been very successful. For instance, the issue about the prohibition of torture has been subject to various studies in international law. This forbiddance is treated nowadays as a compulsory rule, named as jus cogens, particularly in the regional systems of human rights protections. Although the jurisprudence of the European Court is ahead of the ICHR, the recognition of prohibition of torture

\footnotetext{
${ }^{1}$ Acadêmica do $4^{\circ}$ ano de Direito da Faculdade de Direito da Universidade Federal do Paraná.

${ }^{2}$ A sigla 'CIDH' será utilizada neste artigo como abreviação de Corte Interamericana de Direitos Humanos.
}

Revista Brasileira de Direito Internacional, Curitiba, v.5, n.5, jan./jun.2007 
practice as a jus cogens in the American system has been reached, becoming, in this case, an absolute and unconditional standard, even in situations considered critical.

Revista Brasileira de Direito Internacional, Curitiba, v.5, n.5, jan./jun.2007 


\section{INTRODUÇÃO}

O Direito Internacional Público, embora seja reconhecidamente um "direito dos consensos", no qual as relações se dão através da coordenação, e não da subordinação, vem cada vez mais reconhecendo uma nova e ainda "desconhecida" espécie de norma: as normas imperativas.

Embora, via de regra, as relações internacionais se dêem de forma negocial, a fim de preservar as soberanias dos Estados envolvidos, estas normas imperativas, também denominadas de jus cogens, não admitem disposição em contrário nem podem ser revogadas, ainda que as partes assim o desejem.

Neste sentido, o presente trabalho abordará uma dessas normas em especial: a proibição da prática de tortura e, mais especificamente, como ela é tratada no sistema Interamericano de Direitos Humanos. Embora já existam posicionamentos no sentido de reconhecer a proibição de tortura como jus cogens, também no âmbito interamericano, essas práticas ainda são verificadas.

A análise dessa proibição assume grande importância no continente não apenas porque muitos Estados americanos passaram recentemente por governos ditatoriais, mas também devido aos vários abusos que a população ainda sofre, mesmo sob uma proteção de governos supostamente democráticos, que muitas vezes se mostram incapazes de prevenir ou mesmo punir violações dessa natureza.

Apesar de as legislações internas proibirem as práticas de tortura e tratamentos desumanos, como é o caso do Brasil ${ }^{3}$, verifica-se que uma atuação mais efetiva é essencial para proteção dos direitos humanos nesse continente, principalmente na prevenção e na punição dos sujeitos que a praticam.

\footnotetext{
${ }^{3}$ No Brasil, a proibição de tortura e tratamentos desumanos está positivada na Constituição Federal, artigo $5^{\circ}$, inciso III: "ninguém será submetido a tortura nem a tratamento desumano ou degradante. Ainda há referência no inciso XLIII, o qual considera a tortura crime inafiançável e insuscetível de graça ou anistia.
}

Revista Brasileira de Direito Internacional, Curitiba, v.5, n.5, jan./jun.2007 


\section{SISTEMA INTERAMERICANO DE DIREITOS HUMANOS}

O pacto de San José da Costa Rica, ou Convenção Interamericana de Direitos Humanos, deu início à instauração de um sistema interamericano de proteção aos direitos humanos. Esta Convenção foi assinada em 1969, na cidade de São José, na Costa Rica, em uma conferência da Organização dos Estados Americanos (OEA), e entrou em vigor em 1978.

Em 1999 entrou em vigor o Protocolo de San Salvador. Como a própria Convenção prevê a possibilidade de elaborar protocolos adicionais para a inclusão progressiva de direitos e liberdades em seu regime de proteção, este protocolo, além de reconhecer expressamente em seu preâmbulo que

"os direitos essenciais do homem não derivam do fato de ser ele
nacional de determinado Estado, mas sim do fato de ter como
fundamento os atributos de pessoa humana, razão porque justificam
uma proteção internacional, de natureza convencional, coadjuvante ou
complementar à que oferece o direito interno dos Estados
americanos",

inclui vários outros direitos ao rol daqueles já consagrados na Convenção.

O Sistema Interamericano de Direitos Humanos foi criado como um sistema regional de proteção dos Direitos Humanos, de modo a efetivar a tutela desses Direitos no continente americano, seguindo a tendência inaugurada pela Corte Européia de Direitos Humanos, da década de 50 e mais tarde seguida pelo continente africano, com a recente entrada em vigor a Carta Africana dos Direitos Humanos e dos Povos, em 1986.

Nesse sentido, Richard Bilder afirma que

As cortes simbolizam e fortalecem a idéia de que o sistema internacional de direitos humanos é, de fato, um sistema de direitos legais, que envolve direitos e obrigações juridicamente vinculantes. Associa-se a idéia de Estado de Direito com a existênia de Cortes independentes, capazes de proferir decisões obrigatórias e vinculantes. ${ }^{4}$

\footnotetext{
${ }^{4}$ BILDER, Richard. Possibilities for development of new international judicial machanisms. In: Louis Henkin e John Lawrence Hargrove (eds.). Human rights: an agenda for the next century, n. 26, p. 326-7. Apud: PIOVESAN, Flávia. Direitos Humanos e Justiça Internacional, p. 32.
}

Revista Brasileira de Direito Internacional, Curitiba, v.5, n.5, jan./jun.2007 
Em que pese a existência de um sistema universal de proteção, a prática demonstra que um a única jurisdição internacional não é suficiente para garantir que sejam cumpridos e preservados os direitos constantes nos tratados internacional, principalmente quando se tratam de países sob regimes ditatoriais e autoritários.

Estudos de organizações não-governamentais demonstram que a efetivação dos direitos humanos está diretamente relacionada à democracia. Dessa forma, é fundamental que a sociedade civil tenha condições de participar do governo, e que este seja legítimo para aplicar, promover e garantir direitos fundamentais a seus cidadãos. ${ }^{5}$

No que diz respeito ao continente americano, embora hoje a tendência seja a consolidação de governos democráticos, não se pode dizer que exista uma efetiva proteção e promoção dos direitos humanos. A história recente do continente demonstra que boa parte dos Estados americanos passaram por longos períodos ditatoriais e vem, aos poucos, passando por uma reconstrução política, jurídica e social.

Apesar de a doutrina e a jurisprudência da CIDH caminhar no sentido de fortalecer esses direitos, seguindo tendências apontadas nas Corte Internacional de Justiça e Corte Européia de Direitos Humanos, observa-se que ainda há muito a ser feito e desenvolvido. É nesse sentido que a Human Rights Watch indica diretrizes que possibilitariam uma maior proteção e efetivação dos direitos humanos pela CIDH:

O Sistema Inter-americano de Direitos Humanos deve ser reformulado e reforçado das seguintes maneiras:

- fazer com que o sistema e o processo de revisão pública da situação dos direitos humanos se tornem mais efetivos.

- reforçar a Comissão e o Tribunal Inter-americano, assim como as medidas preventivas provisionais ligadas ao sistema, através do reconhecimento da jurisdição de todos os países do continente.

- estabelecer um órgão internacional independente criado para proteger as pessoas que são obrigadas a abandonar a região onde vivem.

\footnotetext{
${ }^{5}$ Apontamentos feitos pela Human Rights Watch.
}

Revista Brasileira de Direito Internacional, Curitiba, v.5, n.5, jan./jun.2007 
- garantir a implementação efetiva do direito de asilo e do status de refugiado nos países que ainda não adotaram este direito, adotando regulamentos nacionais de acordo com as medidas internacionais relevantes.

- incluir nos procedimentos do Tribunal Inter-americano, um mecanismo destinado à participação das vítimas ou de seus representantes, além de exigir transparência nos procedimentos e critérios.

- reconhecer as organizações não-governamentais como membros consultores junto à OEA e adotar uma Declaração Inter-americana de Proteção aos Defensores dos Direitos Humanos. ${ }^{6}$

Contudo, mesmo no Brasil, um país que vem com o passar dos anos consolidando sua democracia, é possível observar graves violações aos direitos humanos, inclusive no que diz respeito ao objeto do presente trabalho: as práticas de tortura. Como observou a Human Rights Watch, o combate a tortura não avançou significativamente no país, sendo sua prática indentificada principalmente em instituições do Estado, as quais deveriam reprimi-la.

Em junho do ano passado, a Secretaria Especial dos Direitos Humanos da Presidência da República também criou o Comitê Nacional para Prevenção e Controle da Tortura, composto por autoridades públicas e representantes da sociedade civil, e encarregado de propor e monitorar mecanismos de combate à prática, assim como realizar visitas de inspeção a locais de detenção. afirma.A tortura, no entanto, na avaliação da Human Rights Watch, permanece grande no Brasil. 'Relatórios apontam que policiais e agentes penitenciários torturam pessoas sob sua custódia como forma de punição, intimidação e extorsão. A polícia também usa a tortura como meio de obter informações ou confissões forçadas de pessoas suspeitas de terem cometido crimes'?

Importante ressaltar que as Cortes regionais não se excluem, devendo, pelo contrário, ser complementares, convivendo de maneira harmoniosa para a realização dos direitos humanos.

Ainda, conforme afirma PIOVESAN, estes sistemas são importantes para o denominado processo de justicialização dos direitos humanos, pois

\footnotetext{
${ }^{6}$ Material utilizado no Curso de Cátedra em homenagem à Sérgio Vieira da Melo, ministrado na Universidade Federal do Paraná, no $1^{\circ}$ semestre de 2006.

7 Brasil não avança no combate às violações de direitos humanos. Disponível em: http://www.direitos.org.br/index.php?option=com_content\&task=view\&id=2470\&ltemid=2, publicada em 18/01/2007; acesso em 27/10/2007.
}

Revista Brasileira de Direito Internacional, Curitiba, v.5, n.5, jan./jun.2007 
buscam internacionalizar esses direitos, permitindo e contribuindo de maneira positiva para sua promoção e proteção. ${ }^{8}$

A autora ainda aponta algumas vantagens de se manter esses sistemas regionais, pois na medida em que há um menor número de Estados envolvidos, mais fácil seria chegar a um consenso político. Além disso, ao menos na teoria, as decisões dessas Cortes refletiriam com maior autenticidade as peculiaridades e os valores históricos de cada povo, resultando numa aceitação mais espontânea por parte da população. Além disso, aponta-se que

O instrumento global deve conter um parâmetro normativo mínimo, enquanto o instrumento regional deve ir além, adicionando novos direitos, aperfeiçoando outros, levando em consideração as diferenças peculiares em uma mesma região ou entre uma região e outra. ${ }^{9}$

Embora passível de críticas, já que muitos apontam que a CIDH muitas vezes assume uma posição 'tímida' frente aos direitos humanos, não se pode deixar de reconhecer sua importância para a consolidação desses direitos na região.

\subsection{OS PROCEDIMENTOS INTERNOS NA COMISSÃO E NA CIDH}

O sistema interamericano de proteção dos Direitos Humanos é composto pela Comissão Interamericana de Direitos Humanos e pela Corte Interamericana de Direitos Humanos. Ambos foram instituídos pela Convenção Americana de Direitos Humanos de 1969, que entrou em vigor em 1978, e são reconhecidamente competentes para conhecer de assuntos relacionados com o cumprimento dos compromissos assumidos pelos Estados-partes da Convenção, conforme estabelecido em seu artigo 33.

\footnotetext{
8 PIOVESAN, Flávia. Direitos Humanos e Justiça Internacional: um estudo comparativo dos sistemas regionais europeu, interamericano e africano. São Paulo: Saraiva, 2006.

${ }_{9}^{9}$ Regional Promotion and protection of human rights: twenty-eighth report of the Commission to Study the Organization of Peace, 1980, in: Henry Steiner, material do Curso Internacional Law and Human Rights, Harvard Law School, 1994. Apud: PIOVESAN, Flávia. Direitos Humanos e Justiça Internacional: um estudo comparativo dos sistemas regionais europeu, interamericano e africano. São Paulo: Saraiva, 2006, p. 54.
}

Revista Brasileira de Direito Internacional, Curitiba, v.5, n.5, jan./jun.2007 
A Comissão é composta por sete membros, eleitos a título pessoal pela Assembléia Geral da Organização, por um período de 4 (quatro) anos.

O artigo 41 estabelece as funções e atribuições da Comissão. São elas:

a) estimular a consciência dos direitos humanos nos povos da América;

b) formular recomendações aos governos dos Estados membros, quando o considerar conveniente, no sentido de que adotem medidas progressivas em prol dos direitos humanos no âmbito de suas leis internas e seus preceitos constitucionais, bem como disposições apropriadas para promover o devido respeito a esses direitos;

c) preparar os estudos ou relatórios que considerar convenientes para o desempenho de suas funções;

d) solicitar aos governos dos Estados membros que lhe proporcionem informações sobre as medidas que adotarem em matéria de direitos humanos;

e) atender às consultas que, por meio da Secretaria-Geral da Organização dos Estados Americanos, lhe formularem os Estados membros sobre questões relacionadas com os direitos humanos e, dentro de suas possibilidades, prestar-lhes o assessoramento que eles lhe solicitarem;

f) atuar com respeito às petições e outras comunicações, no exercício de sua autoridade, de conformidade com o disposto nos artigos $44^{\circ}$ a $51^{\circ}$ desta Convenção; e

g) apresentar um relatório anual à Assembléia Geral da Organização dos Estados Americanos.

É importante observar que para submeter uma denúncia ou petição à Comissão, relatando violações de normas da Convenção por um Estado-parte, não há exigência de ser um Estado, podendo qualquer pessoa ou grupo de pessoas, ou mesmo entidade não-governamental reconhecida em um ou mais Estados-membros da Organização apresentá-la. ${ }^{10}$

No entanto, para que a petição seja acolhida faz-se necessário o preenchimento de três requisitos: o esgotamento dos recursos da jurisdição interna; a observância do prazo de seis meses, a partir da data de notificação da decisão definitiva; e a inexistência de litispendência internacional.

O esgotamento dos recursos internos apenas não será possível nas hipóteses em que não existir, na legislação interna do Estado, o devido processo legal para a proteção do direito pleiteado ou se o requerente tiver sido

${ }^{10}$ Convenção Interamericana de Direitos Humanos, artigo 44.

Revista Brasileira de Direito Internacional, Curitiba, v.5, n.5, jan./jun.2007 
impedido de esgotar tais recursos. Ainda, poderá um caso chegar à Comissão se houver demora injustificada do Estado em verificar a denúncia e emitir uma decisão. A exigência de tais requisitos se justifica na medida em que os próprios tratados internacionais, principalmente de direitos humanos assinados pelos Estados, impõem a eles o dever de assegurar às vítimas o acesso à justiça no âmbito interno, para ter seus direitos reconhecidos e tutelados. Também servem para reforçar que este sistema internacional não é substitutivo aos sistemas nacionais, mas complementares a eles.

A Comissão sempre buscará uma solução amistosa para a composição do conflito. Se esta não for possível, redigirá um relatório expondo os fatos e suas conclusões, podendo, inclusive, fazer recomendações ao Estado e estipular prazo para seu cumprimento. Se nenhuma atitude for tomada, e a Comissão julgar importante para a proteção dos direitos humanos, poderá submeter o caso à Corte Interamericana de Direitos Humanos, o órgão jurisdicional desse sistema. Ainda, poderá decidir por publicar o caso em seu relatório anual, se o Estado não tomar ou não as medidas adequadas.

O fato de as decisões da Comissão não terem força de sentença, não significa que não possuem coercitividade, pois caso o Estado não tome as medidas indicadas e a Comissão decida incluir o caso no relatório, poderá haver grande repercussão internacional. Por isso diz-se que a atuação se restringe ao 'power of shame' ou 'power of 'embarrassment' da comunidade internacional.

As disposições a respeito da Corte estão previstas no capítulo VIII da Convenção. Ela é formada por sete juízes, que poderão ser reeleitos uma vez, podendo exercer função consultiva ou jurisdicional.

A função consultiva está prevista no artigo 64, e refere-se a consultas que os Estados poderão fazer sobre a interpretação da Convenção ou mesmo de outros tratados concernentes à proteção dos direitos humanos nos Estados americanos. A pedido do Estado, a Corte também poderá emitir pareceres sobre a compatibilidade entre qualquer de suas leis internas e esses tratados. Esse é um campo de bastante destaque na $\mathrm{CIDH}$, pois tem contribuído de forma bastante significativa para a conceituação dos direitos humanos.

Revista Brasileira de Direito Internacional, Curitiba, v.5, n.5, jan./jun.2007 
A função jurisdicional, por outro lado, permite não apenas que a Corte atue no campo contencioso, mas também adote medidas para assegurar 0 cumprimento dos direitos humanos. ${ }^{11}$ As sentenças da Corte são definitivas e inapeláveis, devendo ser fundamentadas. No entanto, diferentemente da Corte Européia de Direitos Humanos, os indivíduos e ONG's não têm acesso à CIDH, pois somente os Estados-parte e a Comissão têm direito de submeter um casso à decisão da Corte.

Este fato é bastante criticado pela doutrina, em especial por Cançado Trindade, pois restringiria 0 acesso à proteção dos direitos humanos. Entretanto, convém ressaltar que também a CEDH inicialmente não previa essa possibilidade, passando a permitir o acesso de indivíduos apenas com a entrada em vigor do Protocolo 9, de 1990.

\footnotetext{
${ }^{11}$ Artigo 63, 2: Em casos de extrema gravidade e urgência, e quando se fizer necessário evitar danos irreparáveis às pessoas, a Corte, nos assuntos de que estiver conhecendo, poderá tomar as medidas provisórias que considerar pertinentes. Se se tratar de assuntos que ainda não estiverem submetidos ao seu conhecimento, poderá atuar a pedido da Comissão.
}

Revista Brasileira de Direito Internacional, Curitiba, v.5, n.5, jan./jun.2007 


\title{
3 A PROIBIÇÃO DA PRÁTICA DE TORTURA COMO UMA NORMA IMPERATIVA DE DIREITO INTERNACIONAL PÚBLICO
}

No âmbito internacional existem alguns tratados para prevenir e punir a tortura, como a 'Convenção contra a tortura e outros tratamentos ou penas cruéis, desumanos ou degradantes', das Nações Unidas. A Organização das Nações Unidas criou, inclusive, um comitê contra a tortura, composto por 10 especialistas, responsáveis pela análise de casos em que há práticas descritas em sua convenção. Nesta, há definição de tortura, no artigo $1^{\circ}$, como sendo:

\begin{abstract}
(...) qualquer ato pelo qual dores ou sofrimentos agudos, físicos ou mentais, são infligidos intencionalmente a uma pessoa a fim de obter, dela ou de uma terceira pessoa, informações ou confissões; de castigála por ato que ela ou uma terceira pessoa tenha cometido ou seja suspeita de ter cometido; de intimidar ou coagir esta pessoa ou outras pessoas; ou por qualquer motivo baseado em discriminação de qualquer natureza; quando tais dores ou sofrimentos são infligidos por um funcionário público ou outra pessoa no exercício de funções públicas, ou por sua instigação, ou com o seu consentimento ou aquiescência.

Não se considerará como tortura as dores ou sofrimentos que sejam consequiências unicamente de sanções legítimas, ou que sejam inerentes a tais sanções ou delas decorram.
\end{abstract}

No âmbito interamericano, as discussões desenvolvem-se no mesmo sentido. A Organização dos Estados Americanos (OEA), além de trazer dispositivos contra esta prática na Convenção Americana sobre Direitos Humanos, criou a Convenção Interamericana para Prevenir e Punir a Tortura, em 1985, ratificada pelo Brasil em 20.07.1989. Conforme apontado no próprio texto da Convenção, seu objetivo é reafirmar que

\begin{abstract}
todo ato de tortura ou outros tratamentos ou penas cruéis, desumanos ou degradantes constituem uma ofensa à dignidade humana e uma negação dos princípios consagrados na Carta da Organização dos Estados Americanos e na Carta das Nações Unidas, e são violatórios dos direitos humanos e liberdades fundamentais proclamados na Declaração Americana dos Direitos e Deveres do Homem e na Declaração Universal dos Direitos do Homem ${ }^{12}$
\end{abstract}

\footnotetext{
${ }^{12}$ Disponível em:

http://www.pge.sp.gov.br/centrodeestudos/bibliotecavirtual/instrumentos/cartagena.htm, Acesso em 27/10/2007.
}

Revista Brasileira de Direito Internacional, Curitiba, v.5, n.5, jan./jun.2007 
Isso porque a prática do Direito Internacional demonstra que para ser tornar efetiva a prevenção e a punição dessas práticas, é necessário que haja mecanismos de proteção regionais, caso contrário, não seria possível efetivar o conteúdo das normas universais.

Contudo, embora no continente americano, vários países já tenham ratificado esta Convenção ${ }^{13}$, não são raros os casos de pessoas submetidas a práticas de torturas, principalmente em prisões, como uma forma mais 'rápida' para obter informações. Em muitos desses casos, a própria sociedade admite essas práticas, legitimando-a em situações emergenciais, quando visar a proteger a população.

Vários países da América Latina enfrentaram longos anos sob regimes ditatoriais,

Também com base nesse fundamento observam-se as constantes práticas de tortura verificadas pelos Estados Unidos da América, em vários países do mundo, inclusive em Estados Latino-americanos, como é o caso da base de Guantânamo, em Cuba.

Recentemente o Senador norte-americano John McCain propôs a chamada Emenda McCain, a qual proibiria todo funcionário norte-americano de dispensar tratamento ou castigo cruel, desumano ou degradante. A polêmica em torno desta Emenda se refere ao fato de que, ainda hoje a tortura é vista como meio eficaz, que deve ser utilizado pelo Estado quando houver a necessidade de preservar um 'bem maior'.

No entanto, a proibição à prática de tortura, reconhecida com jus cogens, impede qualquer forma de ponderação de valores. Uma norma de jus cogens é absoluta, não podendo ser derrogada em nenhuma hipótese. Tatyana S. Friedrich, citando Verdross, afirma que as regras de jus cogens poderiam ser divididas em três grupos: ${ }^{14}$

\footnotetext{
${ }^{13}$ Países que já ratificaram: Argentina, Bolívia, Brasil, Chile, Colômbia, Costa Rica, Equador, El Salvador, Guatemala, México, Panamá, Paraguai, Peru, República Dominicana, Suriname, Uruguai e Venezuela.

${ }^{14}$ FRIEDRICH, Tatyana S. As Normas Imperativas de Direito Internacional Público jus cogens. Belo Horizonte: Fórum, 2004, p. 90.
}

Revista Brasileira de Direito Internacional, Curitiba, v.5, n.5, jan./jun.2007 
a) são contrárias a jus cogens as regras de um tratado que abusam do direito de terceiro estado, sem o consentimento dele e de forma que se torne impossível para ele cumprir com suas obrigações internacionais;

b) são regras de jus cogens todas as regras criadas com objetivo humanitário, porque surgem com vistas ao maior interesse da humanidade como um todo;

c) também são regras com caráter de jus cogens aquelas previstas na Carta da ONU e que proíbem o uso da força;

Embora seja inegável que a norma que proíbe a tortura foi criada com objetivo humanitário e está prevista em instrumentos normativos internacionais, bem como nas legislações internas dos Estados, ainda há quem defenda essas práticas.

Por estas razões é imprescindível que a proibição à prática de tortura seja cada vez mais se fortaleça como norma imperativa de Direito Internacional, isto é, como jus cogens, para que as violações possam ser reprimidas e evitadas. O menor desenvolvimento da doutrina $e$ as jurisprudência no âmbito interamericano da teoria do jus cogens, se comparada às aplicações verificadas no sistema europeu de proteção de direitos humanos, deve servir de incentivo para que haja uma gradativa ampliação do conteúdo material do jus cogens também nesse continente, de modo a efetivar os direitos humanos presentes não apenas na Convenção Interamericana de Direitos Humanos e no Protocolo de São Salvador, mas também em outras convenções de caráter universal, já que protegem direitos essenciais ao ser humano e devem ser respeitados e protegidos independentemente de qualquer política econômica ou governamental por parte do Estado.

Já nos relatórios da Comissão de Direitos Humanos da ONU de 1996 e 1997 enfatizava-se que a proibição contra tortura possuía natureza de jus cogens, afirmando que "in all human rights instruments the prohibition of torture belongs to the group of rights from which no derogation can be made". ${ }^{15}$

\footnotetext{
${ }^{15}$ FRIEDRICH, Tatyana S. As Normas Imperativas de Direito Internacional Público jus cogens. Belo Horizonte: Fórum, 2004, p. 99-100.
}

Revista Brasileira de Direito Internacional, Curitiba, v.5, n.5, jan./jun.2007 
O tema também foi abordado no Tribunal Penal Internacional da exluguslávia, no caso Le Procureur v. Anto Furundzija. Neste caso, houve o reconhecimento da proibição de tortura na sentença condenatória. ${ }^{16}$

O tratamento dispensado a esta norma pelo Sistema Interamericano de Diritos Humanos também merece atenção, já que a menciona com jus cogens em seus relatório, votos e sentenças.

${ }^{16}$ FRIEDRICH, Tatyana S. As Normas Imperativas de Direito Internacional Público jus cogens. Belo Horizonte: Fórum, 2004, p. 139.

Revista Brasileira de Direito Internacional, Curitiba, v.5, n.5, jan./jun.2007 


\section{O RECONHECIMENTO DA PROIBIÇÃO DA PRÁTICA DE TORTURA NA CIDH}

Pode-se afirmar que a jurisprudência da Corte Interamericana de Direitos Humanos tem contribuído de maneira bastante significativa para 0 avanço da proteção dos direitos humanos no continente americano, principalmente com o reconhecimento de direitos absolutos e inderrogáveis, jus cogens, e com a elevação da norma que proíbe as práticas de tortura a esse status. Numa região que as principais violações aos direitos humanos ocorrem através de assassinatos, execuções sumárias, torturas, violência policial e impunidade e que sobretudo encontra-se num período de transição para a democracia, tratar da tortura sob uma perspectiva internacional é de grande importância.

Um passo importante foi dado na sentença proferida no caso Bámaca Velásquez vs. Guatemala a CIDH reconhece que a tortura também pode ser psicológica, e não apenas física. Nesse caso, afirmou-se que

\footnotetext{
Cuando los familiares conocen que la persona está siendo objeto de torturas, padecen "un sufrimiento que es incluso mayor al real de la tortura física", por tratarse de tortura psicológica de duración prolongada. La posibilidad de que el detenido sea sometido a torturas, es "un sufrimiento insoportable para las personas que lo saben", y aunque puede resultar menos doloroso el presuponer que aquél ha muerto, ello constituye un pensamiento inaceptable, pues "al pensarlo muerto [se lo está] matando", entonces se vuelve a considerar que el detenido se encuentra con vida, lo cual implica que está siendo torturado, y esto genera "un círculo vicioso de pensamientos torturantes.
}

No entanto, o principal avanço foi o reconhecimento da norma que proíbe a tortura como jus cogens pela $\mathrm{CIDH}$. Este reconhecimento se deu em razão do caso Maritza Urrutia, cuja sentença foi proferida em 27 de novembro de 2003, e foi abordado no Relatório Anual elaborado pela Corte, referente ao ano de 2003:

A Corte se referiu à proibição absoluta e irrevogável da tortura,
mesmo nas circunstâncias mais difíceis, tais como guerra, luta contra
o terrorismo e quaisquer outros delitos. Estabeleceu que a proibição

Revista Brasileira de Direito Internacional, Curitiba, v.5, n.5, jan./jun.2007 
absoluta da tortura, em todas as suas formas, "pertence hoje ao domínio de jus cogens internacional". Considerou também que as ameaças e o perigo real de submeter uma pessoa a lesões físicas constitui, em determinadas circunstâncias, "tortura psicológica". ${ }^{17}$

Assim, observa-se que a jurisprudência da Corte Interamericana de Direitos Humanos vem se desenvolvendo de maneira bastante significativa, seguindo tendências apontadas não apenas pelo sistema universal de proteção, mas principalmente pelo sistema regional europeu, o que reforça a importância em fortalecer estes mecanismos regionais. Além disso, embora ainda haja muito a ser feito, a CIDH demonstra a preocupação em aumentar o conteúdo do jus cogens, como forma de aumentar a proteção dos cidadãos, preservando um mínimo de dignidade.

Cançado Trindade, em um de seus votos, ressalta a importância na ampliação do conteúdo do jus cogens na região. Afirma que

(...) até início de 2004 a Corte Interamericana vinha sendo, reconhecidamente, um dos tribunais internacionais contemporâneos que mais vinha contribuindo para a evolução do conteúdo material do jus cogens, seguida pelo Tribunal Penal Internacional ad hoc para a ExIugoslávia. Por alguma razão que escapa a minha compreensão, ultimamente parece ter se refreado em sua construção doutrináriojurisprudencial a respeito.

(...) deveria ter ido mais além quanto a estes últimos, estendendo o domínio do jus cogens também ao direito de acesso à justiça lato sensu, aí compreendidas as garantias do devido processo legal ${ }^{18}$

Além disso, na mesma ocasião confirma que pertence ao conteúdo do jus cogens a proibição de tortura, afirmando que

38. Na presente Sentença no caso Ximenes Lopes versus Brasil, a Corte Interamericana advertiu que o direito à integridade pessoal, consagrado na Convenção Americana, tem por "finalidade principal" a "prohibição imperativa da tortura e penas ou tratamentos cruéis,

\footnotetext{
17 Relatório da Presidência da Comissão de Assuntos Jurídicos e Políticos referentes às observações e recomendações dos Estados membros sobre o relatório anual da Corte Interamericana de Direitos Humanos 17/05/2004, referente ao ano de 2003. Disponível em http://scm.oas.org/doc_public/PORTUGUESE/HIST_04/CP12961P07.doc; Acesso em 27/10/2007).

${ }_{18}$ VOTO SEPARADO DO JUIZ A.A. CANÇADO TRINDADE, Disponível em http://www.global.org.br/docs/votocancado.doc; Acesso em 27/10/2007.
} 
desumanos ou degrandantes", não admitindo, pois, suspensão em "circunstância alguma" (par. 126). A Corte já o havia advertido em sua Sentença (de 18.08.2000) no caso Cantoral Benavides versus Peru (pars. 95-96). Em outras palavras, a referida proibição recai no domínio do jus cogens.

As discussões a respeito das práticas de tortura se mostram bastante atuais, principalmente após os atentados terroristas de 11 de setembro. Embora bastante utilizadas em guerras e por governos autoritários, sabe-se que estão presentes mesmo em governos democráticos e, muitas vezes, até são legitimadas pela sociedade, já que é vista como uma forma rápida e eficiente de obter informações do inimigo. Por esse motivo, o tema também foi discutido na "Reunião de Peritos Governamentais sobre as melhores práticas e experiências nacionais na adoção de medidas contra terrorismo, sob a perspectiva dos direitos humanos", que aconteceu em 12 e 13 de fevereiro de 2004. O relatório desta reunião, o Senhor Florentín Meléndez, membro da Comissão Interamericana de Direitos Humanos presente na reunião, destacou

a existência de direitos que não são revogáveis em nenhuma circunstância, como a proibição da tortura de detidos, a dispensa de tratamento compatível com o direito internacional aplicável em tempos de paz e de guerra e o respeito ao devido processo. Assinalou que este último aspecto é o que permite conhecer a verdade e que, ao negá-lo, pode-se correr o risco de punir um inocente e deixar impune $\mathrm{o}$ ato terrorista que se procura sancionar. ${ }^{19}$

A proibição à tortura é mais uma vez abordada no âmbito do sistema interamericano por Hélio Bicudo, no caso Martinez Villareal, no qual manifesta sua opinião divergente no que tange a condenação à pena de morte, afirmando que o direito a vida é protegido pela Convenção Americana sobre os Direitos Humanos. Dessa forma que a condenação de um indivíduo a pena capital impõe um sofrimento e angústia imensurável enquanto esperam a execução. Regasta o conceito de tortura da Convenção Interamericana para prevenir e sancionar a Tortura, subscrita em Cartágena de Índias, Colômbia, a 9 de

\footnotetext{
${ }^{19}$ Relatório da Reunião de Peritos Governamentais sobre as melhores práticas e experiências nacionais na adoção de medidas contra terrorismo, sob a perspectiva dos direitos humanos. Disponível em http://scm.oas.org/doc_public/PORTUGUESE/HIST_04/CP12485P07.doc; Acesso em 27/10/2007.
}

Revista Brasileira de Direito Internacional, Curitiba, v.5, n.5, jan./jun.2007 
dezembro de 1985, a qual define tortura como "todo ato realizado intencionalmente pelo qual se inflijam a uma pessoa penas ou sofrimentos físicos ou mentais, com fins de investigação criminal, como meio intimidatório, como castigo pessoal, como medida preventiva, como pena ou qualquer outro fim" (artigo $2^{\circ}$ ).

Ao concluir, embora não utilize o termo 'jus cogens', dá à norma que proíbe a tortura conteúdo de norma absoluta, internacionalmente aprovada:

\begin{abstract}
Assim, a proibição absoluta, pela Convenção Européia, da tortura e das penas ou tratamentos desumanos ou degradantes mostra que o artigo $3^{\circ}$, em referência, consagra um dos valores fundamentais das sociedades democráticas. Salienta o julgado que no mesmo sentido dispõem o pacto Internacional de 1966 relativo aos direitos civis e políticos e a Convenção Americana dos Direitos do Homem, de 1969, ao proteger, em toda sua extensão e profundidade, os direitos da pessoa humana. Trata-se, conclui, de uma norma internacionalmente aprovada.
\end{abstract}

É dessa forma que a jurisprudência internacional vai se consolidando no que diz respeito aos direitos humanos. Nesse sentido, há um importante papel a ser desenvolvido pelo sistema interamericano de direitos humanos a fim de efetivar tais direitos. Ao menos no que tange à proibição de práticas de tortura a norma já foi internacionalmente reconhecida como jus cogens. No entanto, ainda há outros direitos que merecem ser observados. 


\section{CONSIDERAÇÕES FINAIS}

Embora seja possível afirmar que há consenso quanto à proibição da prática de tortura, não são incomuns notícias sobre ela. São várias as formas de tortura utilizadas em guerras, principalmente quando se deseja obter informações do inimigo. No entanto, esta prática também tem ganhado espaço em tempos de paz. Muitas vezes as práticas são perpetuadas dentro de instituições do próprio Estado, com a conivência da sociedade.

Apesar de o senso comum repudiar tais práticas, em alguns casos a população a admite, como se esta fosse a única forma eficiente para obter a confissão de um criminoso e posteriormente sua punição. É dessa forma que a tortura de presos muitas vezes é vista como "um mal necessário".

No entanto, a tortura é contra todas as normas de direito internacional, pois além de violar gravemente os direitos inerentes aos seres humanos, acaba com qualquer resquício de dignidade, principalmente nos casos que envolvem presos. Tal como ocorria nos períodos de ditadura, ainda hoje é possível identificar casos de torturas em presídios e delegacias dos Estados americanos.

Dessa forma, as práticas de tortura devem ser severamente punidas. Nesse sentido, a consolidação da norma que a proíbe como jus cogens, tanto no âmbito regional com global, contribui significativamente para a redução da impunidade. No entanto, é importante que haja manifestações no sentido de prevenir tais práticas, para que não haja violação dos direitos do indivíduo, e a promoção de sua dignidade.

Revista Brasileira de Direito Internacional, Curitiba, v.5, n.5, jan./jun.2007 


\section{REFERÊNCIAS}

Brasil não avança no combate às violações de direitos humanos. Disponível em:

http://www.direitos.org.br/index.php?option=com_content\&task=view\&id=2470\& Itemid=2, publicada em 18/01/2007; acesso em 27/10/2007

Convenção Interamericana de Direitos Humanos. Disponível em http://www.cidh.oas.org/Basicos/Portugues/c.Convencao_Americana.htm, acesso em 27/10/2007.

FRIEDRICH, Tatyana S. As Normas Imperativas de Direito Internacional Público jus cogens. Belo Horizonte: Fórum, 2004.

FRIEDRICH, Tatyana Scheila. Sistema Interamericano de Proteção de Direitos Humanos: uma análise a partir do caso Damião Ximenes Lopes. In: Revista Brasileira de Direito Internacional; Núcleo de Estudos em Direito Internacional da UFPR. Curitiba: Sistema eletrônico de revistas, 2005, p. 18-29.

PIOVESAN, Flávia. Direitos Humanos e Justiça Internacional: um estudo comparativo dos sistemas regionais europeu, interamericano e africano. São Paulo: Saraiva, 2006.

Relatório da Presidência da Comissão de Assuntos Jurídicos e Políticos referentes às observações e recomendações dos Estados membros sobre o relatório anual da Corte Interamericana de Direitos Humanos 17/05/2004, referente ao ano de 2003. Disponível em http://scm.oas.org/doc_public/PORTUGUESE/HIST_04/CP12961P07.doc; Acesso em 27/10/2007).

Relatório da Reunião de Peritos Governamentais sobre as melhores práticas e experiências nacionais na adoção de medidas contra terrorismo, sob a perspectiva dos direitos humanos. Disponível em http://scm.oas.org/doc_public/PORTUGUESE/HIST_04/CP12485P07.doc; Acesso em 27/10/2007.

VOTO SEPARADO DO JUIZ A.A. CANÇADO TRINDADE, Disponível em http://www.global.org.br/docs/votocancado.doc; Acesso em 27/10/2007. 